\title{
Effects of grain size on quartz ESR dating of Ti-Li center in fluvial and lacustrine sediments
}

Chun-Ru Liu, Gong-Ming Yin, Fei Han

State Key Laboratory of Earthquake Dynamics, Institute of Geology, China Earthquake Administration, Beijing, 100029, China

\begin{abstract}
The electron spin resonance (ESR) dating method has been introduced into the Quaternary chronology for nearly 40 years and has been successfully used for dating of fluvial and lacustrine sediments. In order to evaluate the possible effect of the sediment grain size on the dating estimate, the parallel ESR dating testing was carried out on quartz grains of five different size fractions ranging from 50 to $450 \mu \mathrm{m}$ extracted from the same fluvial and lacustrine sediment collected close to the M/B boundary at the Donggutuo section, Nihewan Basin, China. The results show that equivalent doses and associated ages vary significantly. However the beta irradiation dose rate of the grains with different sizes accounts for only about $6 \%$ of the total deviation of the dating results. At the same time, the sensitivity of quartz Ti-Li center was calculated based on the additional irradiation. It shows that the larger grains are more sensitive than the smaller ones, which can leads to higher saturate ESR intensity and less equivalent dose. The variations of the sensitivity of quartz Ti-Li center of the grains with different sizes are responsible for the primary deviation of the dating results. The results also suggest that $100-150 \mu \mathrm{m}$ grain size fraction would be priority size for the ESR dating of quartz Ti-Li center on fluvial and lacustrine sediments.
\end{abstract}

Key word: quartz; ESR dating; grain size; Ti-Li center; sediment

\section{Introduction}

ESR dating is one of the independent dating methods applicable for the dating of fluvial and lacustrine sediments older than 100 ka (e.g. Voinchet et al., 2007, 2010; Tissoux et al., 2008; Liu et al., 2010, 2013a, 2013b, 2014). In such sediment, the size of the grain varies from few micron meter to few centimeters, and the sensitivities of both ESR and OSL signals of the quartz showed strong grain size depended effects (Buhay et al., 1988; Pietsch et al., 2008; Fan et al, 2010). The beta ray dose should be considered in detail and accurately calculated (Aitken, 1985, 1998; Adamiec and Aitken, 1998). But, it is unclear whether it can account for the entire effect of the grain size on ESR dating.

In this work, a sample collected in a stratum closed to the Matuyama/Brunhes (M/B) boundary record in the Donggutuo sequence, Nihewan Basin, China, was revisited. This sample used to be dated by ESR method using quartz grains of 105-200 $\mu \mathrm{m}$ and the dating result was consistent with the paleomagnetic age estimate (Liu, et al., 2010). In the present work, the same sediment sample was sieved and split into five fractions with different grain sizes. Each fraction was dated by ESR method using the quartz Ti-Li center. The difference dating results are analyzed to reveal the effect of grain size besides the beta dose effect. 


\section{Samples and Methods}

The sample in this work was collected in the Donggutuo sequence, Nihewan basin, China (Fig. 1; after Zhu et al., 2007). Previous magnetostratigraphical research has confirmed the record in the silty sequence of this site of the M/B palaeomagnetic boundary and an ESR age of $750 \pm 88 \mathrm{ka}$ was obtained using the Ti-Li signal on 105-200 $\mu \mathrm{m}$ quartz grains in a previous study (Liu et al., 2010).

Five fractions of different grain sizes (50-100 $\mu \mathrm{m}, 100-150 \mu \mathrm{m}, 150-200 \mu \mathrm{m}, 200-300 \mu \mathrm{m}$ and 300-450 $\mu \mathrm{m})$ were extracted by wet sieving. Then pure quartz of each fraction was obtained through chemical separation techniques (Liu et al., 2010), and divided into $200 \mathrm{mg}$ aliquots. At the end, these aliquots have received different additional gamma doses ranging from 0 to 10,000 Gy using the ${ }^{60}$ Co gamma source of Peking University.

ESR measurements were carried out on a BRUKER ER041XG X-band spectrometer in a finger dewar cooled to $77 \mathrm{~K}$ with liquid nitrogen in the ESR laboratory of the Institute of Geology, China Earthquake Administration. The experimental parameters were microwave power $5 \mathrm{~mW}$ and modulation amplitude $0.16 \mathrm{mT}$. There are different ways to evaluate the ESR intensity of the Ti center. It seems that the peaks around $\mathrm{g}=1.913, \mathrm{~g}=1.915, \mathrm{~g}=1.931$ and $\mathrm{g}=1.979$ would be the best options (Duval and Guilarte, 2014). The peak at $\mathrm{g}=1.979$ is presumably only made by Ti-Li. The peak at $\mathrm{g}=1.915$ is very likely dominated by $\mathrm{Ti}-\mathrm{H}$ which is influenced by the $\mathrm{Ti}-\mathrm{Li}$ at $\mathrm{g}=1.913$. Unfortunately, it is hardly isolated each peak in X-band ESR spectrometry. The peaks around $\mathrm{g}=1.913$ and $\mathrm{g}=1.979$ shows systematically the highest signal/noise ratio and the best precision (Duval and Guilarte, 2014). For the sample that was used in this study, the relative contribution of the $\mathrm{Ti}-\mathrm{H}$ at $\mathrm{g}=1.915$ center is even smaller (and can be neglected in most case) in the measurement range option of Ti-Li center (see Fig. 2), simply because the amplitude measurement is made from the top peak at $\mathrm{g}=1.979$, rather than from the baseline (Duval and Guilarte, 2014). Rink et al. (2007) and our previous studies (e.g. Liu et al., 2010, 2014) had used the same measurement range of Ti-Li centers to dating sample successfully. Therefore, the Ti-Li center intensity was measured from the top of the peak at $\mathrm{g}=1.979$ to the bottom at $\mathrm{g}=1.913$ in this study. The angular dependence of the ESR signal due to the sample heterogeneity was taken into account. Each aliquot was measured with six rotations, in which scan six times after every $60^{\circ}$ azimuths rotation in the cavity, to obtain the average quartz Ti-Li center ESR intensity.

The dose rate (D) for each group was calculated from the concentrations of uranium, thorium and potassium of the natural sample (Aitken, 1985, 1998; Adamiec and Aitken, 1998) with the adjustment according to the grain size by the method suggested by Grün (1986). Uranium and thorium contents were determined using a thick source Daybreak 530 Model alpha counter. The potassium oxide content was determined by atomic absorption spectrometer. The water content was measured to be $10 \pm 5 \mathrm{wt} \%$. The nowadays burial depth is $5 \mathrm{~m}$, but it was largely higher during geological time, and thus the cosmic dose rate was considered as null in this study. 
For all fractions, the equivalent doses $\left(\mathrm{D}_{\mathrm{E}}\right)$ values and their individual errors were determined from the dose response data fitted with a single saturating exponential (SSE) (Ikeya, 1981; Apers et al., 1981). The fitting function is expressed by:

$$
\mathrm{Y}=\mathrm{S} \cdot\left(1-\exp \left(-\mathrm{L} \cdot\left(\mathrm{X}+\mathrm{D}_{\mathrm{E}}\right)\right)\right)
$$

where $\mathrm{Y}$ is the intensity of the ESR signal of a sample irradiated at the dose $\mathrm{X}$,

$\mathrm{S}$ is the saturation intensity,

$\mathrm{L}$ is the coefficient of sensitivity of the sample,

$D_{\mathrm{E}}$ is the equivalent dose.

In order to know the bleaching quality, three fractions of grain sizes $(50-100,100-150$, and 150-200 $\mu \mathrm{m})$ were also bleached for 0 to $1100 \mathrm{~h}$ by a Höhnle sunlight simulator.

\section{Results and Discussion}

The dose rates were estimated from the radionuclide contents of the sediments. The uranium, thorium and potassium oxide contents of raw analyzed sample are $3.3 \pm 0.2 \mathrm{ppm}, 10.1 \pm 0.5 \mathrm{ppm}$, and $2.35 \pm 0.12 \%$ respectively. The environment doses for the different grain sizes are listed in Table S1. All fractions were etched by $40 \%$ HF for 40 min on the stage of quartz extraction, the alpha dose was omitted in the calculation of dose rate.

The light bleaching characteristics of different grain sizes were showed in Fig. 3. Fig. 3a is the ESR intensity of different grain sizes at different bleaching times. Fig. $3 b$ is the bleaching rate of different grain sizes at different times. The 50-100 $\mu \mathrm{m}$ and 100-150 $\mu \mathrm{m}$ fractions are easier to be bleached to zero than the 150-200 $\mu \mathrm{m}$ fraction (Fig. 3a). After two hundred hours the ESR intensites of quartz Ti-Li center in three fractions are bleached to zero.

The bleaching rates of three fractions are similar (Fig. 3b, Table S2). It suggested that there is no grain size dependent effect when the quartz exposure to light directly. Absolutely, in geological condition it is often not the case because the transportation mode also plays a role in the bleaching. For example, in clear water the bleaching is better than in muddy one (Voinchet et al., 2015). The sample used in this study charaterized by fine-grained brown sands and greyish-yellow silts that is lake-margin (fluvial and lacustrine) sediments (e.g.Wang et al., 2005; Zhu et al., 2007) , and it is possible that the quartz grains have been incompletely bleached before burial. Berteen and Stesmans (2006) and Tissoux et al. (2008) showed the $\mathrm{D}_{\mathrm{E}}$ value of Ti-Li center is often overestimated, probably due to an incomplete bleaching of this center which is dependent of environmental conditions during the processes of sediments deposit. However, in previous study (Liu et al., 2010), the ESR age of quartz Ti-Li center from the same Donggutuo sediment was consistent with the paleomagnetic age estimate under the assumption of complete bleaching. In fact, Voinchet et al. (2015) suggested that the residual dose (for $\mathrm{Al}$ center) represents less than $1 \%$ for fluvial sands (including clear and turbid water) older than $300 \mathrm{ka}$. So complete bleaching was assuming according to both the light bleaching results and previous researches (Liu et al., 2010). 
The sum of an exponential function and a linear term $(\mathrm{E}+\mathrm{L})$ was proposed to describe quartz $\mathrm{Al}$ center growth curves for Lower Pleistocene and Middle Pleistocene sites (e.g. Duval et al., 2009; Duval, 2012; Moreno et al., 2012; Cordier et al., 2012; Voinchet et al., 2013). Comparing the results of two fitting methods ( SSE and E+L) on Ti-Li center curves for our samples, the fitting R-squares of the equivalent doses are similar for every group data and the fitting result errors of the E+L function are bigger than SSE (Table S3). Duval and Guilarte (2014) suggested the empirical function proposed by Woda and Wagner (2007) should be used to fit the dose response curves of the Ti-Li center, since it systematically shows a good fitting and has a relative small number of parameters to fit. Nevertheless the use of this function requires 12-16 experimental points and at least 3-4 points with the irradiation doses over 10 $\mathrm{kGy}$ and up to the doses of $40 \mathrm{kGy}$. In this study, the highest irradiation dose is only $10 \mathrm{kGy}$. Therefore, the function proposed by Woda and Wagner (2007) cannot be used. The SSE function apparently provide $\mathrm{D}_{\mathrm{E}}$ results that are somewhat lower than those derived from the empirical function, but remain overall relatively consistent at $1 \sigma$. So, the equivalent doses were obtained in the present study by the additive dose method using the SSE fitting function method (Fig. 4, Table S4).

According to the previous research (Mejdahl, 1979), the beta dose rate is significantly affected by the grain size. The smaller the particle size, the larger beta dose is. The reason is that the relatively larger surface area for smaller particle takes the high attenuation rate (Mejdahl, 1979), which will cause the small particle to have larger environmental dose rate. Assuming that they take the same equivalent dose, the particle effect due to the beta dose would reach the maximum difference up to $21 \%$, which take about $6 \%$ of the total deviation of the dating results .

The results show that the large fraction $(>200 \mu \mathrm{m})$ takes the smaller equivalent dose. The middle fraction (between 100 and $200 \mu \mathrm{m}$ ) has lower saturated dose and show the higher equivalent dose than the larger fractions. Although the smallest fraction $(50-100 \mu \mathrm{m})$ also have lower saturation dose, it show the smaller equivalent dose than the larger fraction for the lowest natural ESR intensity of Ti-Li center in quartz. If the grain size is more than $100 \mu \mathrm{m}$, the equivalent dose decreases with the increase of the grain size (Fig. 4).

The ESR sensitivity was calculated as the slope of the initial five points on the ESR dose response curve using linear function following Pietsch et al. (2008). The results show that the fractions with larger grain sizes take higher ESR sensitivity in spite of having higher saturation ESR dose (Table S5).

In Table S6, the age by each fraction was calculated according to the results of dose rates in Table S1 and equivalent doses from Fig. 4. The results show that when the size is larger than $100 \mu \mathrm{m}$, the fraction with larger size has a smaller ESR age. The age obtained by the $100-150 \mu \mathrm{m}$ fraction is consistent with the paleomagnetic results (around M/B boundary) and previous ESR analyses on 105-200 $\mu \mathrm{m}$ fractions for Donggutuo sediment. When the grain size is smaller than $100 \mu \mathrm{m}$, the dating result is also underestimated either.

The assumption that the deviation of the dating age is due to the grain size effect from beta dose is not consistent with the final results. The larger grain size fractions get smaller age due to the less equivalent dose caused by higher 
ESR sensitivity. So the grain size effect of the ESR sensitivity dominates the grain size effect on the ESR dating result.

It was suggested that ESR sensitivity of quartz is due to high charge traffic (electrons and electron holes) between electron traps and ESR centers, the amount of this traffic being the absolute number of traps (McKeever, 1985; Hashimoto et al., 1994, 1997; Vartanian et al., 2000), as this number was determined by crystal formation conditions. From the results in Table S5, it could be assumed that the large size fractions take more absolute traps, although the mechanism is still complex and unclear.

In previous studies (e.g. Voinchet et al., 2007; Tissoux et al., 2008; Liu et al., 2010, 2013a, 2013b, 2014), the 100-200 $\mu \mathrm{m}$ fraction has been used to quartz ESR dating of Quaternary sediment sample. In this study, the 50-100 $\mu \mathrm{m}$, $100-150 \mu \mathrm{m}$ and 150-200 $\mu \mathrm{m}$ fractions yield the same results in the error range. But, the age (745 $\pm 149 \mathrm{ka})$ of 100-150 $\mu \mathrm{m}$ fraction is more consistent with the expected age of M/B boundary than other grain size fractions. The bleaching results show that the 50-100 $\mu \mathrm{m}$ and $100-150 \mu \mathrm{m}$ fractions are being more easily bleached than $150-200 \mu \mathrm{m}$ fraction (see Fig. 3a). So, if there are sufficient grains in the fraction, it is better that use the $100-150 \mu \mathrm{m}$ fraction for ESR dating instead of 100-200 $\mu \mathrm{m}$ fraction especially for the fluvial and lacustrine samples. Absolutely, the 100-200 $\mu \mathrm{m}$ fraction is the first choice when there are not sufficient grains in the fraction according to the previous results in the reference of Liu et al.( 2010).

\section{Conclusions}

Different quartz grain size fractions extracted from a sediment sampled at the vicinity of the stratum recording the M/B boundary at Donggutuo site of Nihewan basin was analyzed by ESR to test the grain size effect on ESR dating. Although the $\beta$ dose of different size fractions shows significant size effect, that is not the main source for the size deviation in ESR dating.

The size effect on the ESR sensitivity imposes a larger effect on the dating results. Our results suggest that the age measured on the $100-150 \mu \mathrm{m}$ fraction is consistent with the expected age of a sediment sample from Nihewan basin.

\section{Acknowledgements}

This research was supported by the basic scientific research fund, Institute of Geology, China Earthquake Administration (Grant No. IGCEA1216 and IGCEA1417), and the National Science Foundation of China (Grant No. 41372178). We are very glad to thank Prof. Rainer Grün, Reasearch School of Earth Science, The Australian National University, Canberra, Australia, for discussions. We express our gratitude to Prof. Jean-Jacques Bahain, Département de Préhistoire du Muséum national d'Histoire naturelle, Paris, France, for comments on our manuscript. We would also like to thank Prof. Jiu-Qiang Li for his support with the ${ }^{60}$ Co irradiation at Peking University. 


\section{Reference}

Adamiec, G., Aitken, M.J., 1998. Dose-rate conversion factors: Update. Ancient TL 16, 37-50.

Aitken, M.J., 1985. Thermoluminescence dating. Academic Press, London.

Aitken, M.J., 1998. An introduction to optical dating. Oxford University Press, Oxford.

Apers, D., Debuyst, R., De Cannière, P., Dejehet, F., Lombard, E., 1981. A criticism of the dating by electron paramagnetic resonance (ESR) of the stalagmitic floors of the Caune de l'Arago at Tautavel. In : Absolute dating and Isotope Analysis in Prehistory - Methods and limits (eds H. de Lumley and J. Labeyrie), 533-550, CNRS, Paris.

Beerten, K., Stesmans, A., 2006. Some properties of Ti-related paramagnetic centers relevant for electron spin resonance dating of signal sedimentary quartz grains. Applied Radiation and Isotopes 64, 594-602.

Buhay, W.M., Schwarcz, H.P., Grün, R., 1988. ESR dating of fault gouge: the effect of grain size. Quarernary Science Reviews 7, 515-522.

Cordier, S., Harmand, D., Lauer, T., Voinchet, P., Bahain, J.J., Frechen, M., 2012. Geochronological reconstruction of the Pleistocene evolution of the Sarre valley (France and Germany) using OSL and ESR dating techniques Geomorphology 165-166(1), 91-106.

Duval, M., Grün, R., Falguères, C., Bahain, J.-J., Dolo, J.-M., 2009. ESR dating of Lower Pleistocene fossil teeth: limits of the single saturating exponential (SSE) function for the equivalent dose determination. Radiation Measurements 44, 477-482.

Duval, M., 2012. Dose response curve of the ESR signal of the Aluminum center in quartz grains extracted from sediment. Ancient TL 30(2), 1-9.

Duval, M., Guilarte, V., 2014. ESR dosimetry of optically bleached quartz grains extracted from Plio-Quaternary sediment: Evaluating some key aspects of the ESR signals associated to the Ti-centers. Radiation Measurements, http://dx.doi.org/10.1016/j.radmeas.2014.10.002.

Ikeya, M., 1975. Dating a stalactite by electron paramagnetic resonance. Nature 255, 48-50.

Ikeya, M., 1981. Dating methods and limitation by electron spin resonance (ESR). Absolute dating and isotope analysis in prehistory methods and limits proceeding, Lumley H (de) et Labeyrie J eds, 437-455.

Fan, Y.X., Zhao, H., Chen, F.H., 2010. The equivalent dose of different grain size quartz fractions from lakeshore sediments in the arid region of north China. Quaternary Geochronology 5, 205-211.

Grün, R., 1986. Beta dose attenuation in thin layers. Ancient TL 4(1), 1-8.

Grün, R., 2007. Electron Spin Resonance Dating. Encyclopedia of Quaternary Science, 1505-1516. Elsevier, Oxford.

Hashimoto, T., Sakaue, S., Aoki, H., Ichino, M., 1994. Dependence of TL-property changes of natural quartzes on aluminium contentsaccompanied by thermal annealing treatment. Radiation Measurements 23, 293-299.

Hashimoto, T., Katayama, H., Sakaue, H., Hase, H., Arimura, A., Ojima, T., 1997. Dependence of some radiation-induced phenomena from natural quartz on hydroxyl-impurity contents. Radiation Measurements 27 (2), 243-250.

Liu, C.R., Yin, G.M., Gao, L., Bahain, J. -J., Li, J.P., Lin, M., Chen, S.M., 2010. ESR dating of Pleistoncene archaeological localities of the Nihewan Bsain, North China-Preliminary results.Quaternary Geochronology 5, 385-390.

Liu, C.R., Yin, G.M., Fang, F., Voinchet, P., Deng, C.L., Han, F., Li, J.P., Song, W.J., Wang, D., Bahain, J.-J., 2013a. ESR dating of the Donggutuo Palaeolithic site in the Nihewan Basin, northern China. Geochronometria 40(4), 348-354.

Liu, C.R., Yin, G.M., Zhang, H.P., Zheng, W.J., Voinchet, P., Han, F., Wang, D., Song, W.J., Bahain, J.-J., 2013b. ESR geochronology of the Minjiang River terraces at Wenchuan, eastern margin of Tibetan Plateau, China. Geochronometria 40(4), 360-367.

Liu, C.R., Yin, G.M., Deng, C.L., Han, F., Song, W.J., 2014. ESR dating of the Majuangou and Banshan Paleolithic sites in the Nihewan Basin, North China. Journal of Human Evolution 73, 58-63.

McKeever, S.W.S., 1985. Thermoluminescence of Solids. Cambridge University Press, London.

Mejdahl, V.,1979. Thermoluminescence dating: beta-dose attenuation in quartz grains. Archaeometry21, 61-72. doi: $10.1111 / \mathrm{j} .1475-4754$.

Moreno, D., Falguères, C., Pérez-González, A., Duval, M., Voinchet, P., Benito-Calvo, A., Ortega, A.I., Bahain, J.J., Sala, R., Carbonell, E., Bermúdez de Castro, J.M., Arsuaga, J.L., 2012. ESR chronology of alluvial deposits in the Arlanzón valley (Atapuerca, Spain): Contemporaneity with Atapuerca Gran Dolina site. Quaternary Geochronology 10, 418-423. 
Pietsch, T.J., Olley, J.M., Nanson, G.C., 2008. Fluvial transport as a natural luminescence sensitiser of quartz. Quaternary Geochronology 3, 365-376.

Rink, W.J., Bartoll, J., Schwarcz, H.P., Shane, P., Ber-Yosef, O., 2007. Testing the reliability of ESR dating of optically exposed buried quartz sediments. Radiation Measurements 4, 1618-1626.

Tissoux, H., Toyoda, S., Falguères, C., Voinchet, P., Takada, M., Bahain, J.-J., Despriée, J., 2008. ESR dating of sedimentary quartz from two Pleistocene deposits using $\mathrm{Al}$ and Ti-centers. Geochronometria 30, 23-31.

Vartanian, E., Guibert, P., Rogue, C., Bechtel, F., Schvoerer, M., 2000. Changes in OSL properties of quartz by preheating: an interpretation. Radiation Measurements 32 (5-6), 647-652.

Voinchet, P., Falguères, C., Tissoux, H., Bahain, J.-J., Despriée, J., Pirouelle, F., 2007. ESR dating of fluvial quartz: estimate of the minimal distance transport required for getting a maximum optical bleaching. Quaternary Geochronology 2, 363-366.

Voinchet, P., Despriee, J., Tissoux, H., Falguères, C., Bahain J.-J., Gageonnet, R., Depont, J., Dolo, J.M., 2010. ESR chronology of alluvial deposits and first human settlements of the Middle Loire Basin (Region Centre, France). Quaternary Geochronology 2, 381-384.

Voinchet, P., Yin, G.M., Falguères, C., Liu, C.R., Han, F., Sun, X.F., Bahain J.-J., 2013. ESR dose response of the Al center measured in quartz samples from the Yellow River (China): implications for the dating of upper Pleistocene sediment. Geochronometria 40(4), 341.347.

Voinchet, P., Toyoda, S., Falguères, C., Hernandez, M., Tissoux, H., Moreno, D., Bahain, J.-J., 2015. Evaluation of ESR residual dose in quartz modern samples, an investigation on environment dependence. Quaternary Geochronology, submitted.

Wang, H.Q., Deng, C. L., Zhu, R.X., Wei, Q., Hou, Y.M., Boeda, E., 2005. Magnetostratigraphic dating of the Donggutuo and Maliang Paleolithic sites in the Nihewan Basin, North China. Quaternary Research 64(1), 1-11.

Woda, C., Wagner, G.A., 2007. Non-monotonic dose dependence of the Ge- and Ti-centres in quartz. Radiat. Meas. 42, 1441-1452.

Zhu, R.X., Deng, C.L., Pan, Y.X., 2007. Magnetochronology of the fluvio-lacustrine sequences in the Nihewan basin and its implications for early human colonization of northeast Asia. Quaternary Sciences 27, 5-27.

Figure captions

Fig. 1. Map showing sampling site at Donggutuo, Nihewan basin in North China and its lithostratigraphy, magnetic polarity and correlation with the geomagnetic polarity timescale.

Fig.2 The quartz Ti (Ti-Li and Ti-H) center ESR signal spectrum of natural sample for different grain size fractions. Both $\mathrm{Ti}-\mathrm{Li}$ and $\mathrm{Ti}-\mathrm{H}$ signal are present in our sample. In this study, the Ti-Li center measurement range is from the top of the peak at $\mathrm{g}=1.979$ to the bottom at $\mathrm{g}=1.913$. The scan time is one. The receivers gain values are $7.10 \times 10^{3}, 8.93 \times 10^{3}$, $1.00 \times 10^{4}, 5.64 \times 10^{3}$ and $4.48 \times 10^{3}$ for the fractions of 50-100 $\mu \mathrm{m}, 100-150 \mu \mathrm{m}, 150-200 \mu \mathrm{m}, 200-300 \mu \mathrm{m}$ and $300-450$ $\mu \mathrm{m}$, respectively.

Fig. 3 Light bleaching characteristics of different grain sizes of natural sample. a) The ESR intensitity of different grain sizes at different bleaching times. b) The bleaching rate of different grain sizes at different bleaching times.

Fig. 4 ESR dose response curves of different grain sizes fractions 

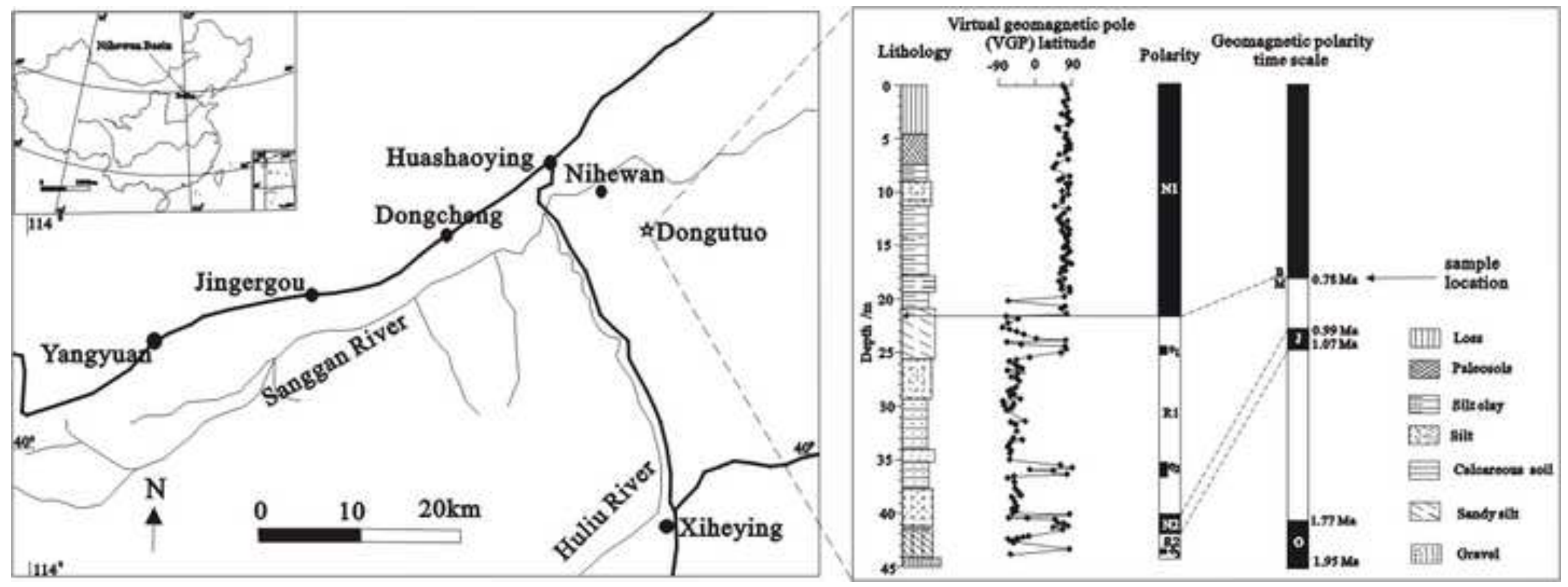


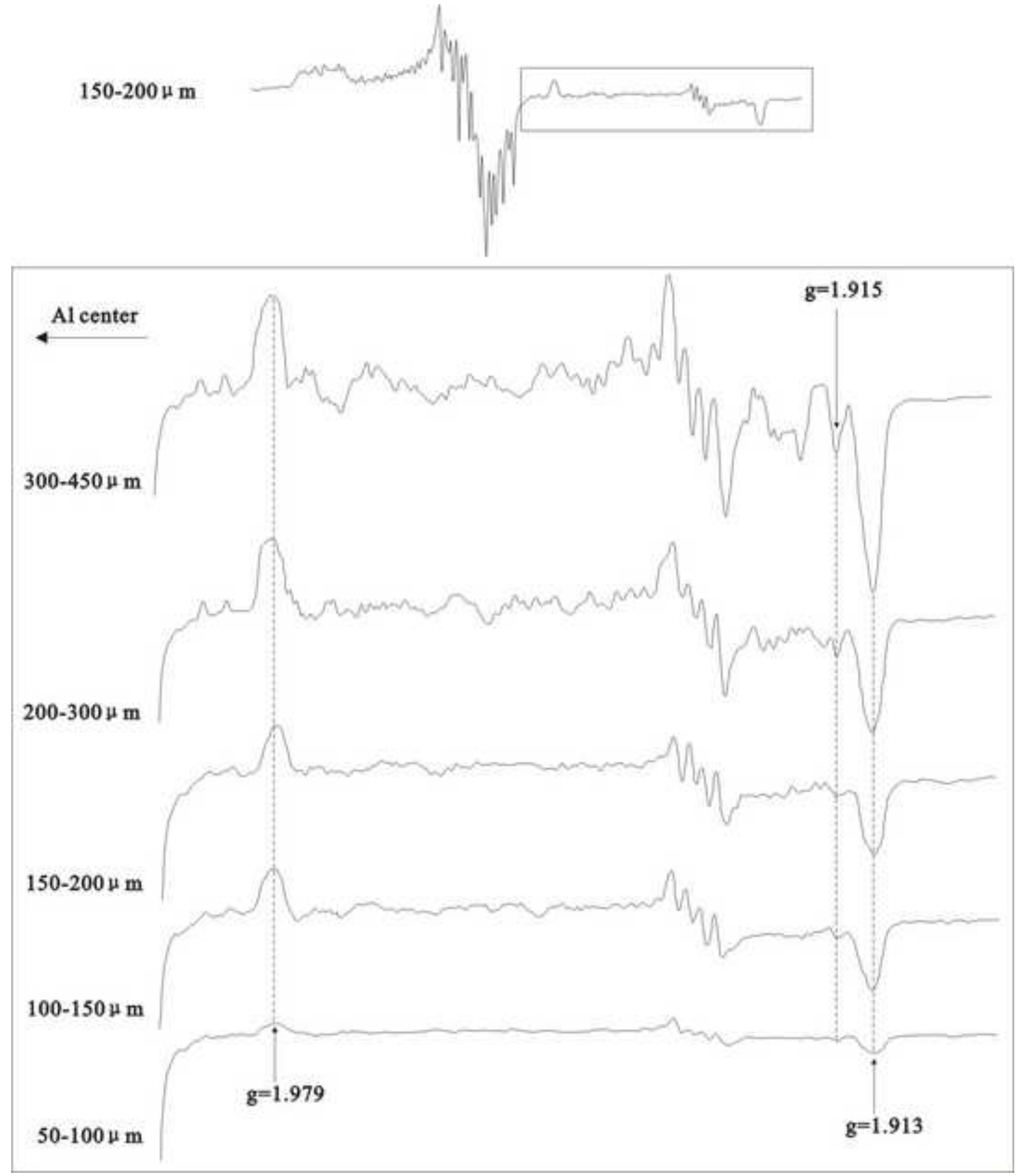



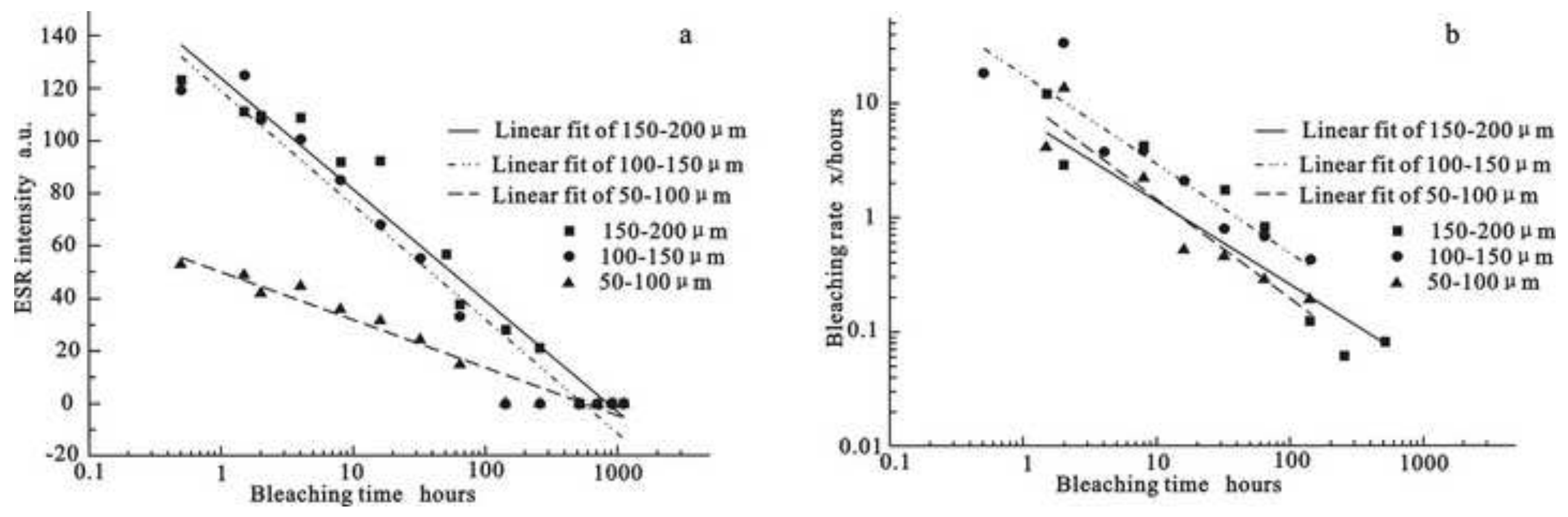
Figure 4
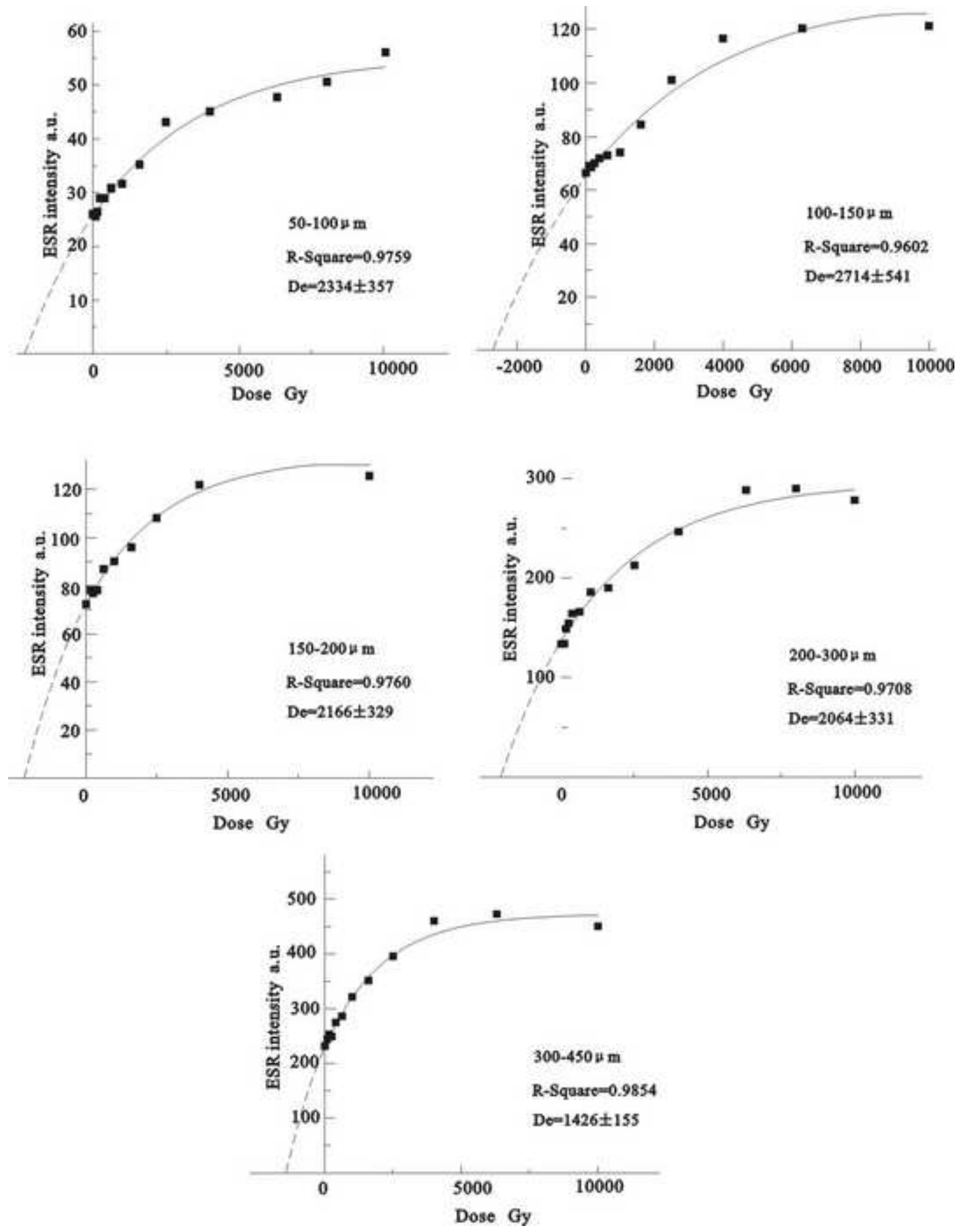